\title{
ALTERAÇÕES BUCAIS MAIS FREQUENTES NO BEBÊ: RELATO DE DOIS CASOS DE CISTOS DE INCLUSÃO
}

\section{MORE FREQUENT ORAL ALTERATIONS IN THE BABY: TWO CASES REPORT OF INCLUSION CYSTS}

\author{
Paulo Renato Martins Vaz * \\ Fernanda Figueira Rodrigues Vieira * \\ Roberto da Gama Silveira *.. \\ José Massao Miasato …
}

\begin{abstract}
RESUMO
Introdução: Os cistos de inclusão do recém-nascido são observados em grupos de dois a seis cistos, embora as lesões possam ocorrer isoladamente, de coloração branca, branco-amarelada ou acinzentada, localizadas na mucosa bucal, podendo desaparecer ainda na fase intrauterina e ser classificadas, de acordo com a localização, como: nódulos de Bohn, cistos da lâmina dentária e pérolas de Epstein. O objetivo deste artigo é relatar dois casos de cistos de inclusão em bebês, diagnosticados como nódulos de Bohn e cistos da lâmina dentária. As lesões são inócuas e nenhum tratamento é necessário. Conclusão: Considerando-se que os cistos de inclusão são alterações frequentes na cavidade oral dos bebês, conclui-se ser imprescindível que odontopediatras e profissionais que atendem crianças nessa faixa etária os reconheçam, atentando para a necessidade de intervenção e, sobretudo, de tranquilizar os pais, normalmente preocupados ao observar essas anomalias em seus filhos.
\end{abstract}

DESCRITORES: Recém-nascido • Mucosa bucal • Odontopediatria

\section{ABSTRACT}

Introduction: The cysts of inclusion of the newborn are observed in groups from two to six cysts, although the lesions can happen separately, of coloration white, white-yellowish or grayish, located in the mouth mucosa, and could still disappear in the intra-uterine phase, and they can be classified, in agreement with the location, as: nodules of Bohn, cysts of the dental sheet and Epstein pearls. The objective of this article is to report two cases of inclusion cysts in babies, diagnosed as nodules of Bohn and cysts of the dental sheet. The lesions are innocuous and no treatment is necessary. Conclusion: Being considered that the inclusion cysts are frequent alterations in the babies' oral cavity, it is concluded to be indispensable that pediatric dentists and professionals that assist children in this age group recognize them, looking at the intervention need and, above all, in the sense of tranquilizing the parents, usually concerned when observing those anomalies in their children.

DESCRIPTORS: Infant-Newborn • Mouth mucosa • Pediatric dentistry

\footnotetext{
* Mestre em Odontopediatria pela Universidade do Grande Rio - UNIGRANRIO e especialista em Saúde Coletiva pela ABO - RJ

** Acadêmica de iniciação científica do $6^{\circ}$ período de Odontologia da Universidade do Grande Rio - UNIGRANRIO

*** Professor do Programa de Mestrado em Odontopediatria da Universidade do Grande Rio - UNIGRANRIO

**** Professor-coordenador do Programa de Mestrado em Odontopediatria da Universidade do Grande Rio - UNIGRANRIO
} 


\section{N T RO DUÇÃ O}

Os cistos de inclusão do recém-nascido são pequenas pápulas assintomáticas, de coloração branca, branco-amarelada ou acinzentada, localizados na mucosa bucal, podendo ser múltiplas e com tamanho variando de 1 a $3 \mathrm{~mm}$. São encontradas em $75 \%$ dos neonatos (Flaitz ${ }^{1}$ 1996), podendo desaparecer ainda na fase intrauterina, e podem ser classificados, de acordo com a localização, como: nódulos de Bohn, cistos da lâmina dentária e pérolas de Epstein 2, 3, 4, 5, 6 .

Considerando-se a necessidade dos odontopediatras e dos cirurgiões-dentistas, que atuam com crianças na mais tenra idade, de conhecerem as alterações bucais mais frequentes nos bebês para que se possa, principalmente, tranquilizar os pais, este artigo tem como objetivo relatar dois casos clínicos de cistos de inclusão em bebês, diagnosticados como nódulos de Bohn e cistos da lâmina dentária.

\section{RELATO DO CASO 1}

Paciente do sexo masculino, leucoderma, 4 meses de idade, compareceu à Bebê-Clínica da Universidade do Grande Rio em 23/03/2009, acompanhado de sua genitora, para a primeira consulta do bebê no PAOPI - Programa de Atenção Odontológica na Primeira Infância da UNIGRANRIO. Ao exame clínico, verificou-se que não havia ainda dentes erupcionados e foi constatada na cavidade oral da criança a presença de uma alteração bucal em formato de pápula isolada, de cor branca, medindo cerca de $1 \mathrm{~mm}$ de diâmetro, localizada na face vestibular do rebordo alveolar inferior direito. A lesão era caracte- rística de nódulos de Bohn e o tratamento proposto foi o acompanhamento clínico trimestral da criança durante as consultas na Bebê-Clínica, além da recomendação de massagem digital suave a ser realizada diariamente pelos pais sobre a alteração. A genitora do bebê, inicialmente atordoada, foi tranquilizada após o diagnóstico e prognóstico favorável.

\section{RELATO DO CASO 2}

Paciente do sexo masculino, faioderma, 13 meses de idade, compareceu à BebêClínica da UNIGRANRIO em 15/06/2009, acompanhado de sua genitora, para consulta de rotina. A responsável relatou queixa de que o bebê, frequentemente, "coçava uma bolinha amarelada na gengiva", segundo ela, um "dentinho" que estava nascendo. Ao exame clínico intraoral do paciente, observou-se que todos os incisivos já haviam erupcionados e foi identificada uma lesão cística unilateral, de cor branco-amarelada, medindo cerca de $3 \mathrm{~mm}$, localizada na linha do rebordo alveolar, na região do primeiro molar inferior direito. A alteração era característica de cistos da lâmina dentária e o tratamento proposto foi o acompanhamento clínico da criança durante suas consultas trimestrais na Bebê-Clínica, além da orientação quanto à massagem suave a ser realizada diariamente pelos pais sobre a lesão. A mãe do bebê, que no início da consulta demonstrava estar emocionalmente abalada, sentiu-se confortada após o diagnóstico e prognóstico favorável.

\section{I SCUSSÃO}

Os nódulos de Bohn são estruturas

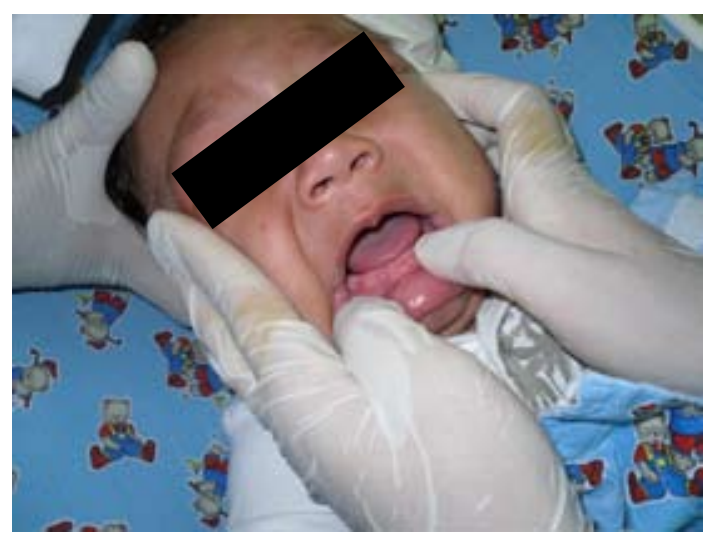

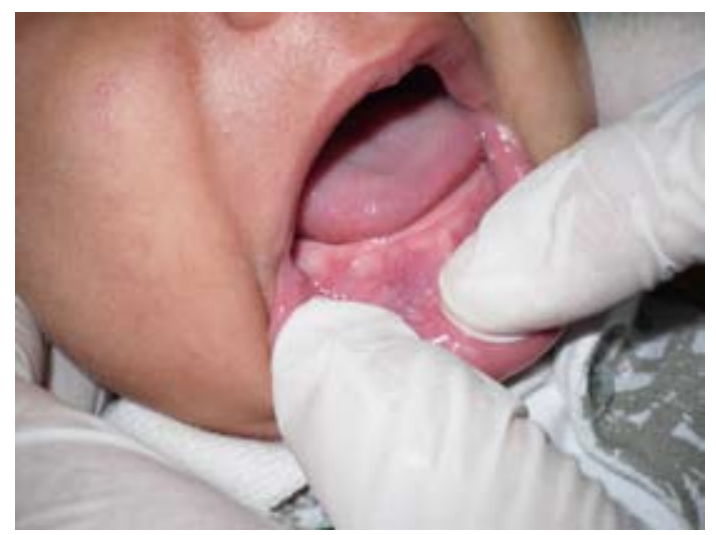

Fotografias 1 e 2: Lesão típica de nódulos de Bohn em registro clínico e em aproximação.
VAZ PRM,

VIEIRA FFR,

SILVEIRA RG,

MIASATO JM.

ALTERAÇÕES

BUCAIS MAIS

FREQUENTES NO

BEBÊE RELATO

DE DOIS CASOS

DE CISTOS DE

INCLUSÃO

175

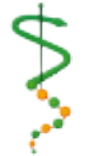

REVISTA DE ODONTOLOGIA DA UNIVERSI DADE CIDADE DE SÃO PAULO

$2010 ; 22(2)$ :

$174-7$, MAI-AGO 


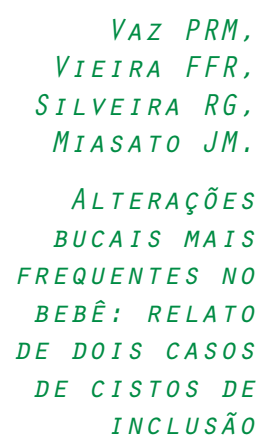

176

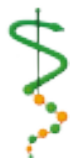

REVISTA DE ODONTOLOGIA DA

UNIVERSIDADE CIDADE DE SÃO

PAULO

$2010 ; 22(2):$ $174-7, M A I-A G O$
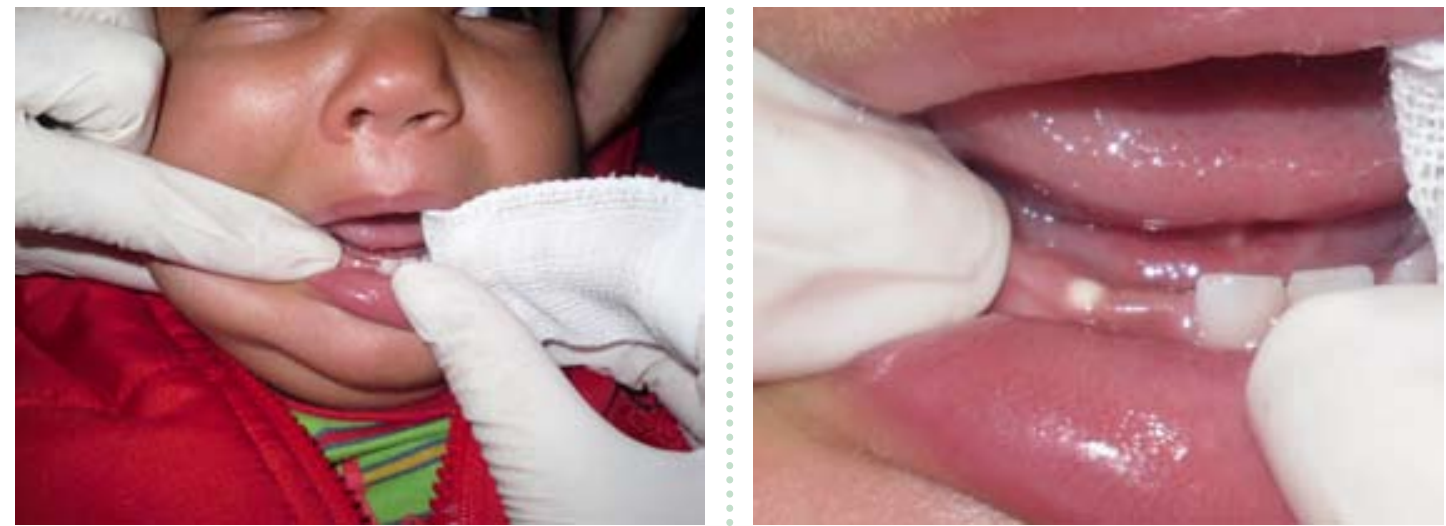

Fotografias 3 e 4: Manifestação bucal característica de cistos da lâmina dentária em registro clínico e em tomada aproximada.

que aparecem tipicamente como nódulos múltiplos ao longo do rebordo alveolar do recém-nascido, localizando-se, em especial, na face vestibular ou palatina, mas longe da rafe palatina como remanescentes de glândulas mucosas. Os cistos da lâmina dentária, nos recém-nascidos, são normalmente bilaterais, na linha do rebordo alveolar e localizados na região de primeiro molar. Do ponto de vista histológico, o cisto intacto conterá resíduos de queratina e uma camada epitelial delgada. São estruturas remanescentes da lâmina dentária que permaneceram na mucosa do rebordo alveolar depois da formação do dente e proliferaram para formar pequenos cistos queratinizados. As pérolas de Epstein são cistos queratinizados localizados na região da rafe média palatina e estão presentes em cerca de $80 \%$ dos bebês recém-nascidos. As pérolas de Epstein são consideradas remanescentes do tecido epitelial aprisionado ao longo da rafe palatina à medida que o feto cresce (Machado et al. ${ }^{7}$ 2005).

Segundo Neville et al. ${ }^{8}$ (2004), os cistos são pequenas pápulas brancas ou branco-amareladas, de 1 a $3 \mathrm{~mm}$ de tamanho, muito comuns e têm sido relatados em 65 a 85\% dos recém-nascidos, sendo frequentemente observados em grupo de dois a seis cistos, embora as lesões possam ocorrer isoladamente. As lesões são inócuas e nenhum tratamento é necessário. Segundo Walter et al. ${ }^{9}$ (1999), são alterações semelhantes a pequenas bolas branco-amareladas que ocorrem entre 75,9 a $92 \%$ em crianças recém-natas de 1 a 2 dias de idade, as quais, na maioria das vezes, desaparecem no primeiro mês de vida, porém algumas aumentam de tamanho e, por volta do $3^{\circ}$ mês, tornam-se volumosas, grandes e bastante visíveis, e podem persistir ou aparecer tardiamente, fornecendo uma falsa impressão de abscesso. A conduta deve ser a observação com o acompanhamento do desenvolvimento que é involutivo, e aconselhar massagem digital suave. A tendência da alteração é desaparecer em algumas semanas, porém quando o seu volume é exagerado recomenda-se a marsupialização.

Baldani et al. ${ }^{10}$ (2001), em pesquisa da prevalência de alterações na cavidade oral de 200 bebês, na faixa etária de 0 a 24 meses, atendidas nas clínicas de bebês públicas do município de Ponta Grossa - PR, verificaram que $21 \%$ dos bebês apresentaram alterações bucais e, considerando-se apenas as crianças afetadas, as alterações mais prevalentes foram os cistos de inclusão (35,7\%). O estudo revelou, ainda, que não foi necessário tratamento em $76,2 \%$ dos casos. Os resultados indicaram que a maioria das alterações bucais nessa faixa etária são benignas e não requerem nenhum tipo de tratamento específico.

Em ambos os casos aqui relatados, as mães estavam excessivamente preocupadas com o bem-estar dos filhos e a prática clínica demonstra que situações semelhantes a essas não são raras. Frequentemente, o odontopediatra pode observar conduta paterna superprotetora, com preocupação exagerada ao mínimo sinal de desconforto do bebê, podendo transformá-lo em uma criança mimada e medrosa. Contudo, também são observados pais não afetuosos 
com seus filhos, com atitudes que beiram à violência, colaborando para a criação de uma criança desobediente e agressiva.

O odontopediatra deverá analisar o comportamento dos pais, pois condutas impróprias destes poderão corroborar para o desenvolvimento de uma criança avessa aos procedimentos odontológicos, ainda que restritos à prevenção. O sucesso do tratamento dependerá da lapidação comportamental de pais e filhos a ser realizada pelo profissional.

\section{CONCLUSÃO}

Os cistos de inclusão são alterações frequentes na cavidade oral dos bebês, sendo imprescindível que odontopediatras e profissionais que atendem crianças nessa faixa etária os reconheçam, atentando para a necessidade de intervenção e, sobretudo, no sentido de tranquilizar os pais, normalmente preocupados ao observar essas anomalias em seus filhos.

\section{REFERÊNCIAS}

1. Flaitz CM. Patologias e alterações dos tecidos moles orais. In: Pinkhan JR. Odontopediatria - da infância à adolescência. São Paulo: Artes Médicas; 1996.

2. Bezerra S, Costa I. Oral conditions in children from birth to 5 years: the findings of a children's dental program. J Clin Pediatr Dent. 2000; 25(1): 78-81.

3. Binnie WH. Periodontal cysts and epulides. Periodontol 2000. 1999 Oct; 21: 1632.

4. Cameron A, Widmer R. Manual de odontopediatria. São Paulo: Santos; 2001.

5. Corrêa MSNP. Odontopediatria na primeira infância. São Paulo: Santos; 1998.

6. Hayes PA. Hamartomas, eruption cyst, natal tooth and Epstein pearls in a newborn. ASDC. J Dent Child. 2000 Sep-Oct; 67(5): 365-8.

7. Machado MAAM, Silva SMB, Abdo RCC. Odontologia em bebês - protocolos clínicos, preventivos e restauradores. São Paulo: Santos; 2005.

8. Neville BW, Damm DD, Allen CM, Bouquot JE. Patologia oral e maxilofacial. Rio de Janeiro: Guanabara Koogan; 2004.

9. Walter LRF, Ferelle A, Issao M. Odontologia para o bebê. São Paulo: Artes Médicas; 1999.

10. Baldani $\mathrm{MH}$, Lopes $\mathrm{CML}$, Scheidt WA. Prevalência de alterações bucais em crianças atendidas nas clínicas de bebês públicas de Ponta Grossa - PR, Brasil. Pesqui Odontol Bras. 2001 out-dez; 15(4): 302-307.

Recebido em: 02/10/2009

Aceito em: 16/03/2010 